\title{
Memória e identidade: a (re)construção da figura do militar nazi na metaficção historiográfica de Uwe Timm e de Marcel Beyer ${ }^{1}$
}

\author{
Rogério Paulo Madeira \\ Universidade de Coimbra
}

Resumo: A minha comunicação debruça-se sobre duas obras histórico-ficcionais que, no contexto da Alemanha reunificada, abordam o passado nacional-socialista, designadamente a narrativa (auto)biográfica Am Beispiel meines Bruders (2003), de Uwe Timm, e o romance Spione (2000), de Marcel Beyer. Em ambos os textos representativos da metaficção historiográfica (Linda Hutcheon), os respectivos narradores, movidos pela curiosidade em relação a objectos pessoais pertencentes a antepassados, partem em busca da verdadeira identidade dos entes queridos, perdida no labirinto da memória do Terceiro Reich e silenciada no seio da família durante décadas de pós-guerra. Recorrendo aos conceitos de memória cultural/colectiva, memória comunicativa (Jan e Aleida Assmann/Astrid Erll) e pós-memória (Marianne Hirsch), entre outros, centrar-me-ei na análise da problemática da (re)construção das figuras do irmão e antigo soldado das Waffen-SS, na obra de Uwe Timm, bem como do avô do narrador e antigo oficial da Wehrmacht, na obra de Marcel Beyer.

Palavras-chave: Literatura e História, metaficção historiográfica, memória, identidade, nacional-socialismo, Segunda Guerra Mundial, Holocausto

Zusammenfassung: Mein Beitrag befasst sich mit zwei geschichtsfiktionalen Texten, die sich im Kontext des wiedervereinigten Deutschlands mit der NS-Vergangenheit beschäftigten: Uwe Timms (auto)biographische Erzählung Am Beispiel meines Bruders (2003) und Marcel Beyers Roman Spione (2000). In beiden Texten, die als Beispiele für historiographische Metafiktion gelten (Linda Hutcheon), werden die jeweiligen Erzähler aus 
Neugier auf zurückgelassene Gegenstände aufbrechen auf der Suche nach der wirklichen Identität ihrer geliebten Vorfahren, die sich im Labyrinth der Erinnerung an das Dritte Reich verbirgt und in der Nachkriegszeit in der eigenen Familie verschwiegen wurde. Mit Rückgriff auf Konzepte des kulturellen bzw. kollektiven und kommunikativen Gedächtnisses (Jan e Aleida Assmann/Astrid Erll) sowie der postmemory (Marianne Hirsch), u.a., wird die Problematik der (Re)Konstruktion einerseits der Figur des Bruders und ehemaligen Soldaten der Waffen-SS im Werk Uwe Timms, und andererseits der Figur des Großvaters des Erzählers und ehemaligen Wehrmachtsoffiziers im Werk Marcel Beyers im Mittelpunkt der Untersuchung stehen.

Schlüsselbegriffe: Literatur und Geschichte, historiographic metafiction, Gedächtnis, Identität, Nationalsozialismus, Zweiter Weltkrieg, Holocaust

A maioria dos estudos teóricos sobre a memória e a identidade vindos a lume nas últimas décadas tem exprimido um amplo consenso em relação ao papel decisivo desempenhado pelo trabalho de rememoração/memória no processo de reconstrução e preservação da identidade, quer individual, quer colectiva (cf. Nünning 2005: 47). A complexidade da relação dialéctica entre os referidos conceitos (ibidem) adquire particular importância no domínio da literatura de expressão alemã que versa temas relativos ao passado nacional-socialista, designadamente a problemática da culpa e a representação de figuras comprometidas com o regime hitleriano.

No panorama histórico-literário e cultural da Alemanha reunificada, tem-se assistido a uma autêntica vaga de obras histórico-ficcionais dadas à estampa por autores representativos não apenas da primeira geração do pós-guerra (as testemunhas directas do nazismo e da Segunda Guerra Mundial), como Günter Grass ou Martin Walser, mas também da geração intermédia (ou geração de 68) e da terceira geração, a dos netos das testemunhas do Terceiro Reich. São precisamente dois dos mais destacados nomes de cada uma dessas gerações mais jovens que são objecto deste breve estudo comparativo: em primeiro lugar, Uwe Timm e, depois, Marcel Beyer. De resto, ambos os autores saltaram para a ribalta justamente através da publicação de narrativas que empreendem viagens 
histórico-ficcionais ao passado nacional-socialista, ${ }^{2}$ contribuindo dessa forma para a fundamentação da tese da viragem da memória ("Wende des Erinnerns") na sequência da queda do Muro de Berlim (cf. Beßlich et al. 2006: 7). ${ }^{3}$ Cada um destes ficcionistas representa, assim, uma "geração posterior" àquela que testemunhou directamente a realidade do nacional-socialismo e da guerra, tendo somente acesso ao passado traumático através de relatos orais e escritos, de imagens e outras formas de transmissão de memória, facultados pela geração mais velha; ou seja, através do conjunto de informações que Marianne Hirsch (2008: 106) designa por postmemory.

Começo pelo autor da geração intermédia (n. 1940, Hamburgo) que, em 2003, — só após a morte do seu último parente mais próximo, a sua irmã mais velha — faz a primeira incursão na escrita autobiográfica com a publicação da obra Am Beispiel meines Bruders (cf. Kammler 2006: 11ss., 54ss.). Liberto de qualquer constrangimento pessoal, Timm estabelece $a b$ initio, através do uso do pronome pessoal ("meines") no próprio título da obra, o pacto autobiográfico (cf. Reichold 2014: 140s.), assumindo a voz de narrador de primeira pessoa e, consequentemente, a subjectividade inerente a este tipo de instância mediadora na reconstrução da biografia do irmão, Karl-Heinz Timm, que, em 16 de Outubro de 1943, perdera a vida na frente Leste como jovem soldado da Waffen-SS, na sequência de ferimentos graves, quando o autor/narrador contava apenas três anos de idade.

O que suscita - 60 anos após a tragédia que atingiu a família - a partida de Timm em busca da verdadeira identidade do irmão mais velho, perdida algures nos meandros da memória colectiva e familiar do Terceiro Reich, é a descoberta de uma pequena caixa de cartão ("Pappschachtel") envolta num manto de silêncio paterno e materno, salpicado de saudosos discursos encomiásticos, uma caixa com alguns haveres do antigo soldado nazi, religiosamente guardada pela mãe, falecida em 1991. Essa autêntica Gedächtniskiste [caixa de memória] - expressão cunhada por Aleida Assmann (apud Galli 2007: 104) — inclui, além de pequenos objectos pessoais (como uma escova e pasta de dentes ou um pente com cabelos louros), algumas fotografias avulsas, desfocadas e dois tipos de testemunhos escritos fundamentais: a escassa correspondência trocada com os pais e o diário de guerra que o jovem soldado da SS-Division Totenkopf escrevera em segredo nos campos de batalha 
da frente Leste. À luz da teoria sobre a memória, os pertences do malogrado irmão servem de pretexto para a construção da pós-memória (cf. Hirsch, 2008: 103-128) e constituem — juntamente com as recordações da infância, os sonhos e as cogitações do próprio eunarrador, bem como relatos e histórias de terceiros - exemplos consagrados de memória comunicativa ou familiar, os quais - pela mão do escritor e por via da obra literária — são deslocados do espaço privado para o espaço público da memória cultural. ${ }^{4}$

0 autor/narrador abdica da narração linear e vai urdindo o tecido narrativo, bastante heterogéneo e complexo, diga-se, com recurso à técnica de montagem. Na verdade, aos referidos materiais acresce um conjunto variegado de outras fontes - como um discurso de Himmler, cartas e diários de generais, notícias e deliberações militares, citações de outros documentos históricos e de textos literários, ensaísticos e historiográficos ${ }^{5}$ fontes que o eu-narrador (e investigador) colige e, não raro, complementa com os seus próprios comentários e reflexões de cariz meta-historiográfico e literário (cf. Reichold 2014: 145-149, e Alves, 2010: 265-274). A polifonia decorrente da estratégia narrativa permite a distanciação crítica por parte do autor/narrador e reduz, consequentemente, a subjectividade da representação histórico-biográfica numa obra particularmente híbrida também do ponto de vista discursivo e genológico, em conformidade com os preceitos caraterísticos da metaficção historiográfica, enunciados por Linda Hutcheon (1988) e Ansgar Nünning (1995; 2002: 541-569), entre outros, nos respectivos estudos acerca da ficção histórica da pós-modernidade.

Uwe Timm obedece ao imperativo "Erinnerung, sprich." [Fala, memória.] (BB 36) — citado do título da obra autobiográfica de Vladimir Nabokov —6 e é efectivamente à memória comunicativa que o autor/narrador passa a palavra quando inicia o processo de averiguação identitária de Karl-Heinz cuja imagem intocável e exemplar fora esculpida pelos pais, ao longo de décadas, por entre demorados e suspeitos silêncios. Quando questionados sobre as razões que terão levado o jovem sonhador e introvertido a alistar-se voluntariamente na Waffen-SS, tanto o pai como a mãe refugiam-se no idealismo e na valentia do falecido e, mesmo directamente confrontados com as imagens televisivas da 
libertação de campos de concentração e de extermínio, ambos distorcem a realidade histórica com o intuito de ilibar por completo o filho mais velho:

Die Mistbande, hieß es, die Verbrecher. Der Junge war aber bei der Waffen-SS. Die SS war eine normale Kampftruppe. Die Verbrecher waren die anderen, der SD. Die Einsatzgruppen. Vor allem die oben, die Führung. Der Idealismus des Jungen mißbraucht. (BB 19)

[A cambada, era o que chamavam aos SS, os criminosos. Mas o rapaz estava na Waffen-SS. A SS era uma unidade de combate normal. Os criminosos eram os outros, os do SD [Sicherheitsdienst], do Serviço de Segurança do Estado. As brigadas de intervenção. Sobretudo os que estavam lá em cima, os líderes. Abusaram do idealismo do rapaz.] $]^{7}$

A insistência dos pais no discurso heroicizante do rapaz calmo, responsável e obediente tende a afastar da mente do irmão mais novo qualquer sombra de responsabilidade ou culpa no que concerne às atrocidades cometidas pelas Waffen-SS no decurso da guerra (aliás, historicamente referenciadas) e culmina, reiteradamente, na estilização do soldado alemão Karl-Heinz Timm como vítima do regime nazi e da guerra. Será, porém, a perscrutação do parco material escrito por ele legado à posteridade a exponenciar as dúvidas de Uwe Timm quanto à fiabilidade de um tão perfeito retrato. Repare-se no seguinte excerto do diário do irmão:

Feb. 27.

Gelände wird durchkämmt. Viel Beute! dann geht es wieder weiter vor.

Feb. 28.

1 Tag Ruhe, große Läusejagd, weiter nach Onelda.

Es war eine dieser Stellen, an denen ich früher innehielt, beim Weiterlesen zögerte. (...) dann dieses: Viel Beute!

Was verbirgt sich dahinter? Waffen? Warum dieses Ausrufezeichen, das sich sonst selten in seinen Notizen findet? (BB 15s.) 
$[27 \mathrm{Fev}$.

Terreno passado a pente fino. Presas com fartura! Depois voltamos a avançar.

$28 \mathrm{Fev.}$

1 dia de descanso, grande caça aos piolhos, avançamos para Onelda.

Este era um daqueles passos em que eu dantes parava e hesitava em prosseguir com a leitura. (...) depois este: Presas com fartura!

O que é que está por detrás disto? Armas? Por quê este ponto de exclamação que aliás é tão raro nas suas notas?]

Trata-se, com efeito, de um dos passos relativos ao ataque levado a cabo pelas tropas alemãs em Carcóvia que mais inquietam o autor/narrador, ameaçando fazer ruir de vez a identidade positiva do irmão edificada pelos pais, durante os anos do pós-guerra, no espaço acomodatício da memória familiar.

Há, no entanto, quase imediatamente a seguir, uma outra entrada - tão breve quanto incisiva - que se revela ainda mais perturbadora, ao ponto de o eu-narrador a fazer ecoar por diversas vezes ao longo da narrativa, qual Leitmotiv lançando sobre o perfil do irmão a sombra horrenda da crueldade:

März 21.

Donez

Brückenkopf über den Donez. 75 m raucht Iwan Zigaretten, ein Fressen für mein MG.

Das war die Stelle, bei der ich, stieß ich früher darauf - sie sprang mir oben links auf der Seite regelrecht ins Auge -, nicht weiterlas, sondern das Heft wegschloß. (BB 16)

[21 de Março.

Donets

Cabeça de ponte sobre o Donez. 75 m Iwan fuma cigarros, um achado para a minha metralhadora.

Este era o passo que quando deparava com ele - e ele saltava-me literalmente à vista no canto superior esquerdo da página -, eu tinha de interromper a leitura, fechar o caderno e pô-lo de lado.] 
Se é certo que a imagem repulsiva do irmão como soldado impiedoso se revela traumática para o narrador-detective, há outros aspetos detectados no decurso dos trabalhos de pesquisa que se revelam igualmente incómodos. É o caso da ausência total de representação das atrocidades e dos crimes de guerra cometidos pelos alemães, quer nas fotos quer nos registos escritos (as cartas e o diário) durante a reconquista de Carcóvia em Março de 1943, o último êxito militar germânico na frente Leste:

Es sind keine Fotos, die gehenkte Russen zeigen oder die Erschießung von Zivilisten, sondern ganz alltägliche, die sich auch in dem Fotoband des Vaters finden und zerstörte Häuser, Straßen, Städte zeigen. Ist das Charkow? Der Bruder war an der Rückeroberung von Charkow beteiligt. 1943. Selbst wenn man unterstellt, daß er an dem Mord an Zivilisten, Frauen und Kinder durch die SS nicht beteiligt war, weil er bei einer Panzereinheit diente, so muß er doch mit den Opfern der Zivilbevölkerung konfrontiert worden sein, den Hungernden, Obdachlosen, den durch Kampfhandlungen Vertriebenen, Erfrorenen, Getöteten. Von ihnen ist nicht die Rede, vermutlich erschienen ihm dieses Leid, diese Zerstörungen und Todesopfer normal, also human. (BB 25)

[Não há fotos que mostrem russos enforcados ou a execução de civis, apenas imagens perfeitamente quotidianas como as que se encontram também no álbum do pai, mostrando casas, ruas, cidades destruídas. Isto é Carcóvia? 0 meu irmão participou na reconquista de Carcóvia. 1943. Mesmo que se parta do princípio de que ele não esteve envolvido no assassínio de civis, mulheres e crianças levados a cabo pelas SS, porque cumpria serviço numa unidade de blindados, ele teve de ser confrontado com as vítimas da população civil, com os famintos, os sem-abrigo, os que fugiam às acções de guerra, os regelados, os assassinados. Não há qualquer referência a eles, presumivelmente aquele sofrimento, aquela destruição e aquelas vítimas mortais pareceram-lhe normais, portanto humanas.]

Tais omissões e silêncios a respeito da extrema violência exercida sobre a população do Leste europeu (no fundo, testemunhos de insensibilidade humana por parte do irmão) são tanto mais surpreendentes porquanto contrastam fortemente com a tristeza e indignação por ele demonstradas face à brutalidade e desumanidade dos Aliados em relação à população civil alemã, nomeadamente as mulheres e as crianças, no decorrer dos bombardeamentos aéreos de Hamburgo, numa carta ao pai com a data de 11 de Agosto de 1943: 
Bei mir ist immer noch alles beim alten, gesund bin ich, zu essen habe ich auch, bloß die Sorgen an zu Hause bleiben dann, täglich werden hier Fliegerangriffe der Engländer gemeldet. Wenn der Sachs bloß den Mißt nachlassen würde [sic]. Das ist doch kein Krieg, das ist ja Mord an Frauen und Kinder - und das ist nicht human. (BB 24)

[Aqui continua tudo na mesma, estou bem de saúde, comida também tenh, continuo é preocupado convosco aí em casa, todos os dias recebemos notícias dos ataques aéreos dos ingleses. Se ao menos eles parassem com essa porcaria. Isso não é nenhuma guerra, isso e mas é crime contra mulheres e crianças e isso é desumano.]

A mesma atitude, denunciadora de duplicidade moral, pode constatar-se noutras cartas de resposta ao pai, em que reage à notícia da destruição maciça da sua cidade natal e da casa paterna, por ocasião da célebre "tempestade de fogo sobre Hamburgo" (Feuersturm von Hamburg) (cf. BB 37).

A propósito de dicotomias, nos antípodas do registo alusivo à liquidação do soldado russo ("Ein Fressen für mein MG." $B B$ 16, 17, 33, 150 [Um achado para a minha metralhadora.]) pode o leitor encontrar uma outra entrada diarística bem mais próxima da morte prematura do jovem soldado ao serviço da Alemanha nazi:

Das ist die letzte datierte Eintragung: Die Fahrt geht weiter.

Danach kommt noch eine undatierte, also zwischen dem 7.8 und seiner Verwundung am 19.9.1943 gemachte Notiz, sorgfältig, in einer runderen Schrift und mit einem deutlicheren Druck des Bleistifts: Hiermit schließe ich mein Tagebuch, da ich für unsinnig halte, über so grausame Dinge wie sie manchmal geschehen, Buch zu führen. (BB 120)

[Este é o último registo datado: $A$ viagem continua.

Depois vem ainda uma outra entrada sem data, portanto entre 7 de Agosto e 19 de Setembro, o dia em que foi ferido, feita de modo cuidadoso, numa caligrafia redonda e com um traço do lápis mais carregado: Termino aqui o meu diário, porque não faz qualquer sentido registar coisas tão horrorosas como as que às vezes acontecem.]

Note-se que o ferimento mencionado pelo eu-narrador obriga à amputação das pernas de Karl-Heiz Timm e não lhe concede mais do que dez dias de vida. A tripla 
ocorrência leitmotívica deste último testemunho escrito que o autor/narrador acolhe, nas suas próprias palavras, como "ein Lichtstrahl in die Finsternis" [um raio de luz na escuridão"] ( $B B$ 147; cf. também $B B$ 154), pelo facto de lhe alimentar a esperança - nunca confirmada nem desmentida pelas pesquisas de Uwe Timm - de que o irmão, num hipotético rebate de consciência ou num assomo de sensibilidade humana, havia recusado colaborar na execução de milhares de judeus civis, incluindo mulheres e crianças, ocorrida naquela área entre Julho de 1942 e Novembro de $1943 .^{8}$

No entanto, e por falta de provas, o balanço mostra-se inconclusivo e a dúvida sobre a verdadeira identidade do irmão exemplar fica a pairar para sempre algures, no labirinto da memória, entre a imagem hedionda do nazi convicto (ou do carrasco) e o perfil idealizado da vítima ingénua ou, quiçá, do resistente anti-nazi (cf. Reichold 2014: 150s.; 154ss.). Não é, certamente, por acaso que Uwe Timm, representante da geração intermédia (ou da pós-memória, se quisermos), - a exemplo do irmão - encerra também ele a obra em apreço com o registo diarístico anteriormente citado (cf. supra, p. 6).

No caso do romance meta-historiográfico Spione [Espiões] (2000), de Marcel Beyer (n. 1965), ficcionista que representa a geração dos netos das testemunhas do Terceiro Reich, a reconstituição identitária dos familiares durante a ditadura nacional-socialista revela-se ainda mais problemática. Aqui, ao contrário do que sucede em Am Beispiel meines Bruders, os veículos de memória comunicativa ao dispor da geração vindoura são ainda mais escassos e não incluem qualquer testemunho escrito nem oral. A acção romanesca, inspirada na série literária infanto-juvenil The Famous Five [Os Cinco] criada por Enid Blyton, resume-se às aventuras de espionagem sobre o passado dos avós protagonizadas, desde o Outono de 1977 - marcado pelo flagelo do terrorismo na RFA —, por um eunarrador anónimo e pelos seus primos Carl, Nora e Paulina, na sequência da descoberta de um velho álbum de fotografias a preto e branco, em geral pouco nítidas e desprovidas de legendas ou anotações de índole cronológica e identificativa. Movidos pela curiosidade em relação à vida das pessoas fotografadas na década de 1930, os jovens esbarram numa espécie de pacto de silêncio absoluto, assinado pelas duas gerações mais velhas, ou seja, a dos avós e, também, a dos próprios pais (cf. $S 180$ / E 188). 
Consequentemente, os quatro primos dedicam-se então à actividade detectivesca de descrição e interpretação dos registos fotográficos, não isenta de assumidos exercícios de especulação subjectiva e, até, de completa efabulação. Na verdade, por um lado, os jovens recriam livremente episódios da história de amor vivida entre o avô - por sinal, um antigo piloto da Luftwaffe - e a verdadeira avó, uma antiga cantora lírica, de origem italiana cuja identidade e existência lhes havia sido ocultada, por imposição da segunda avó, "a velha" ("die Alte", S 306 / E 316), como lhe chamam depreciativamente; por outro lado, eles preenchem com descrições de fotos imaginárias, isto é, perfeitamente fictícias, os espaços em branco deixados pelas fotos arrancadas do álbum por mão desconhecida, mas interessada na ocultação do passado. "Was ich nicht sehen kann, muß ich erfinden." [Tenho de inventar o que não vejo.], afirma taxativamente o eu-narrador. "Ich muß mir Bilder selbst ausmalen, wenn ich etwas vor Augen haben will." [Eu próprio tenho de compor imagens, se quiser ter alguma coisa diante dos olhos.] (S 66 / E 71). ${ }^{9}$

Marcel Beyer instaura, assim, um elevado grau de ficcionalização na reconstrução narrativa da história familiar, pautada com numerosas reflexões de cariz metahistoriográfico e literário, semelhantes à que acabo de citar. Como Silke Horstkotte (2003: 290) e Kathrin Anne Reichold (2014: 244/247) fazem notar, a ausência parcial, ou mesmo total, de informações relativas à contextualização das fotografias, tornam este tipo de repositório de memória extremamente precário. ${ }^{10}$ Repare-se, por exemplo, na forma como o sujeito-narrador introduz a figura do avô enquanto antigo oficial nazi:

Der Mann im Photoalbum trägt auf keinem Bild eine Waffe. Er ist jemand, den wir noch nie gesehen haben, und dennoch haben wir gleich begriffen: Das muß unser Großvater sein.

Sein Gesicht ist nur schlecht zu erkennen, wir haben keine Züge ausgemacht, höchstens ein zurückhaltendes Lächeln, vielleicht auch nur ein Blinzeln, ein Zucken der Mundwinkel im Gegenlicht. Auf vielen Bildern wirft der Mützenschirm einen Schatten über die Augen, und doch ist uns trotz aller Undeutlichkeit klar, daß dieser junge Offizier keine Italieneraugen hat. Wir müssen sie tatsächlich von unserer Großmutter geerbt haben. (S 35; sublinhados meus)

[O homem no álbum de fotografias, em nenhuma imagem transporta uma arma. É alguém que nunca vimos, e, apesar disso, percebemos logo: só pode ser o nosso avô. 
É difícil reconhecer o seu rosto, não conseguimos distinguir traços, no máximo um sorriso tímido, possivelmente só um piscar de olhos, um palpitar dos cantos da boca em contraluz. Em muitas das imagens, a pala do seu boné forma uma sombra sobre os olhos, no entanto, e apesar da falta de nitidez, temos a certeza de que este jovem oficial não tem olhos de italiano, Devemos tê-los, de facto, herdado da nossa avó. (E 38)]

Nem a mera identificação do homem retratado na foto como o avô dos adolescentes está isenta de contradições e é inteiramente segura, vindo minar $a b$ initio qualquer veleidade da geração de espiões em alcançar a verdade absoluta no que respeita ao envolvimento do mais velho membro da família na ditadura nacional-socialista. Há, de resto, outros passos que ilustram o carácter especulativo ou assumidamente fictício da encenação histórico-biográfica deste antigo piloto da Luftwaffe e que, por falta de tempo, me dispenso de citar (cf. p.ex. $S 186$ / E 195). Contudo, se aceitarmos tacitamente a identidade atribuída pelo eu-narrador ao militar fotografado, a reconstrução da figura do avô enquanto colaborador activo em crimes de guerra cometidos pelo regime nazi não pode sofrer qualquer contestação, dado que a sua farda ostenta - numa foto com rara nitidez e beneficiando da inscrição “Rückkehr aus Spanien, Sommer 1937” [Regresso de Espanha, Verão de 1937] (S 118 / E 125) - cuja farda ostenta, dizia, as condecorações obtidas na sequência da participação do piloto na operação secreta da Legion Condor [Legião Condor], a unidade chamada por Hitler a intervir na Guerra Civil Espanhola e responsável pelo bombardeamento aéreo de Guernica, em 26 de Abril de 1937.

No cômputo geral, porém, o romance beyeriano comprova a dificuldade acrescida da geração dos netos na reconstituição da memória comunicativa, acabando por tornar-se refém da precariedade do acesso às fontes em segunda mão, como lhe chama Kathrin Anne Reichold (2014: 237s.). Em jeito de balanço e sob a forma de um derradeiro comentário autorreflexivo, o eu-narrador reconhece a dimensão ficcional da obra que versa matéria histórica e, em especial, a que se propõe desvendar o passado nacional-socialista sob a perspectiva da geração dos netos das testemunhas do Terceiro Reich:

Und nun ist ein erfundenes Familienalbum entstanden, in dem nicht nur unsere Großeltern, unsere Eltern und wir zu sehen sind, sondern genauso auch die Alte, die immer unsichtbar hat bleiben 
wollen. (...) Verwischte Szenerien darunter, zum Teil verwackelte Aufnahmen, doch keine unter ihnen mit der Absicht einer Retuschierung undeutlich gemacht, im Gegenteil: jedes einzelne Bild scheint gewisse Züge ohne jedes Erbarmen ans Licht zu bringen, ungerührt. (S 306; sublinhados meus)

[E agora construiu-se um álbum de família inventado, no qual não se vêem apenas os nossos avós, os nossos pais e nós, mas também a velha que sempre quis ficar invisível. (...) Cenários desfocados, em parte retratos tremidos, não existe, no entanto, uma única imagem que tenha sido retocada/mascarada, antes pelo contrário: todas as fotografias, sem excepção, parecem trazer certos traços à luz do dia, sem dó nem piedade. (E316)]

Para concluir, quero apenas relembrar os aspectos desta breve análise comparativa que me parecem mais relevantes. Ambas as obras, bem ilustrativas da metaficção historiográfica da pós-modernidade, comprovam e reflectem criticamente sobre as dificuldades específicas com que se deparam as gerações da pós-memória no âmbito da reconstrução literária de figuras e de acontecimentos pertencentes ao cada vez mais longínquo, mas sempre traumático, Terceiro Reich. No romance autobiográfico Am Beispiel meines Bruders, a viagem de perscrutação ao passado nacional-socialista, termina na ambivalência, com o autor/narrador, representativo da geração intermédia, conformado diante da incerteza quanto à identidade do irmão Karl-Heinz Timm como culpado e/ou como vítima, confirmando a insuficiência dos repositórios de memória comunicativa e de memória cultural com vista ao apuramento da verdade no que respeita ao passado familiar. No romance Spione, por sua vez, a incursão no passado familiar encetada pelo eu-narrador e pelos outros representantes da terceira geração, sobretudo devido à distância crescente, à precariedade dos repositórios de memória e à ausência quase total de testemunhos escritos e orais, reveste um grau de incerteza e de ficcionalização ainda maiores no que concerne à averiguação do verdadeiro perfil identitário do avô como antigo oficial da Luftwaffe e piloto da Legião Condor. Não obstante, a decepção dos sujeitos-narradores das duas obras em apreço perante a falta de respostas definitivas e de uma saída inteiramente satisfatória do labirinto de memórias, em qualquer dos casos, a viagem terá valido a pena. 


\section{Bibliografia}

Alves, Fernanda Mota (2010), “Erinnerte Geschichte(n): individuelle Identität und kollektives Gedächtnis in Am Beispiel meines Bruders und Der Freund und der Fremde von Uwe Timm", in Peter Hanenberg et al. (Hrsg.), Rahmenwechsel Kulturwissenschaften, Königshausen \& Neumann, Würzburg, 265-274.

Assmann, Aleida (1999), Erinnerungsräume. Formen und Wandlungen des kulturellen Gedächtnisses, München, Beck.

Barner, Wilfried. Hrsg. (2006), Geschichte der deutschen Literatur von 1945 bis zur Gegenwart, 2., erw. Aufl., München, Beck.

Baumgart, Christel (s.d.), "Annäherungen an die Wirklichkeit. Form und Fiktion in Marcel Beyers Roman Spione”. textfindling. Texte zu Literatur, Philosophie, Stummfilm, Politik und Kunst. Kurzgeschichten, Gedichte, http://www.textfindling.de/Beyer/Beyer.html (14.10.2015).

Beßlich, Barbara, Katharina Grätz, Olaf Hildebrand (Hrsg.) (2006), Wende des Erinnerns? Geschichtskonstruktionen in der deutschen Literatur nach 1989, Berlin, Schmidt.

Beyer, Marcel (2003), Espiões, trad. do alemão por Ruth Eberhardt Esteves Correia, Porto, Ambar. $[=E]$

-- (2002), Spione, Frankfurt am Main, Fischer Taschenbuch Verlag (12000). [=S]

Braun, Michael (2008), "Marcel Beyer”, in Heinz Ludwig Arnold (Hrsg.), Kritisches Lexikon zur deutschsprachigen Gegenwartsliteratur (KLG), München, edition text + kritik, 1-14.

Egyptien, Jürgen (2006), Einführung in die deutschsprachige Literatur seit 1945, Darmstadt, Wissenschaftliche Buchgesellschaft.

Erll, Astrid (2005), Kollektives Gedächtnis und Erinnnerungskulturen, Stuttgart/Weimar, Metzler.

Galli, Matteo (2007), "Schuhkartons und Pappschachteln. Uwe Timms mediale 
Gedächtniskisten”, in Friedhelm Marx (Hrsg.), Erinnern, Vergessen, Erzählen. Beiträge zum Werk Uwe Timms, unter Mitarbeit v. Stephanie Catani u. Julia Schöll, Göttingen, Wallstein Verlag, 103-116.

Geppert, Hans Vilmar (2009), Der historische Roman. Geschichte umerzählt - von Walter Scott bis zur Gegenwart, Tübingen, Francke.

Guarda, Filomena Viana (2010), "Zwischen kulturellem Gedächtnis und Familienerinnerung. Zu den Romanen Spione von Marcel Beyer und Himmelskörper von Tanja Dückers", in Peter Hanenberg et al. (Hrsg.), Rahmenwechsel Kulturwissenschaften, Königshausen \& Neumann, Würzburg, 275-286.

Habek, Robert (2001), "Konjunktiva: Marcel Beyers Roman Spione". literaturkritik.de, Nr. 3/Jg. 3, März, http://www.literaturkritik.de/public/rezension.php?rez_id =3425 (consulta: 15.10.2015).

Hielscher, Martin (2007), Uwe Timm, München, Deutscher Taschenbuch Verlag. Hirsch, Marianne (2008), “The Generation of Postmemory”, Poetics Today, 29, 1, 103-128. Horstkotte, Silke (2009), "Fingierte Erinnerung, fokalisierte Fotos: Marcel Beyer, Spione", in H.S. (Hrsg.), Nachbilder: Fotografie und Gedächtnis in der deutschen Gegenwartsliteratur, Köln/Weimar/Wien, Böhlau, 201-211.

Hutcheon, Linda (1988), A Poetics of Postmodernism: History, Theory, Fiction, London, New York, Routledge.

Jaeger, Stephan (2006), "Infinite Closures: Narrative(s) of Bombing in Historiography and Literature on the Borderline between Fact and Fiction", in Wilfried Wilms and William Rasch (eds.), Bombs Away!: Representing the Air War Over Europe and Japan, Amsterdam/New York, Rodopi, 65-79.

Kaempf, Simone (2000), "Marcel Beyer: Die ausgelöschte Großmutter". Rezension von Marcel Beyers Spione. Der Spiegel, 20. September, http://www.spiegel.de/ kultur/literatur/marcel-beyer-die-ausgeloeschte-grossmutter-a-94287.html (14.10.2015). 
Kammler, Clemens (2006), Uwe Timm: »Am Beispiel meines Bruders«, München, Oldenbourg. Kesting, Hanjo \& Axel Ruckaberle. 2009. "Uwe Timm”. in Heinz Ludwig Arnold (Hrsg.), Kritisches Lexikon zur deutschsprachigen Gegenwartsliteratur (KLG), München, edition text + kritik, 1-23.

Kißling, Kristian (2000), "Dieser Roman zerstört sich selbst”. Rezension von Marcel Beyers Spione, http://www.u-lit.de/rezension/marcel-beyer-spione.html (14.10.2015).

Krause, Tilman (2000), "Vier Freunde und die verschwundene Großmutter”. Rezension von Marcel Beyers Spione. Die Welt, 26. August. Também disponível em: http://www.welt.de/print-welt/article530173/Vier-Freunde-und-die-verschwundeneGrossmutter.html (consulta: 14.10.2015).

März, Ursula (2000), “Die Lüge im Visier”. Rezension von Marcel Beyers Spione. Berliner Zeitung, 17. Oktober. Também disponível em: http://www.berliner-zeitung.de/archiv/spione-marcel-beyers-gelungener-versuch-ueber-das-sehen-und-das-sichtbare-die-luegeim-visier,10810590,9843440.html (consulta: 14.10.2015).

Niven, Bill (2007), “Chapter 8: Representations of the Nazi past: perpetrators”, in Stuart Taberner (ed.), Contemporary German Fiction. Writing in the Berlin Republic, New York, Cambridge University Press, 125-141.

Nünning, Ansgar (Hrsg.) (2005), Grundbegriffe der Kulturtheorie und Kulturwissenschaften, Stuttgart/Weimar, Metzler.

-- (2002), "Von der fiktionalisierten Historie zur metahistoriographischen Fiktion: Bausteine für eine narratologische und funktionsgeschichtliche Theorie, Typologie und Geschichte des postmodernen historischen Romans", in Daniel Fulda u. Silvia Serena Tschopp (Hrsg.), Literatur und Geschichte: ein Kompendium zu ihrem Verhältnis von der Aufklärung bis zur Gegenwart, Berlin/New York, De Gruyter, 541-569.

-- (1995), Von historischer Fiktion zu historiographischer Metafiktion. Bd. 1 Theorie, Typologie und Poetik des historischen Romans, Trier, WVT Wissenschaftlicher Verlag. 
Reichold, Kathrin Anne (2014), Arbeit an der Erinnerung. Die Bewältigung der Vergangenheit in der deutschen und spanischen Literatur der Gegenwart, Würzburg, Königshausen \& Neumann.

Taberner, Stuart (2007), "Introduction: literary fiction in the Berlin Republic", in Stuart Taberner (ed.), Contemporary German Fiction. Writing in the Berlin Republic, New York, Cambridge University Press, 1-20.

Taberner, Stuart and Karina Berger (2009), "Introduction", in Stuart Taberner and Karina Berger (eds.), Germans as Victims in the Literary Fiction of the Berlin Republic, Rochester/New York, Camden House, 1-14.

Timm, Uwe (2005), Am Beispiel meines Bruders, München, Deutscher Taschenbuch Verlag (12003). [=BB] (1993), Erzählen und kein Ende. Versuche zu einer Ästhetik des Alltags, Köln, Kiepenheuer \& Witsch.

-- (2009), Von Anfang und Ende. Über die Lesbarkeit der Welt, Köln, Kiepenheuer \& Witsch.

Wasmeier, Marie Louise (2007), "The Past in the Making: Invented Images and Fabricated Family History in Marcel Beyer's Spione", in Julian Preece, Frank Finlay, Ruth J. Owen (eds.), New German Literature: Life-writing and Dialogue with the Arts, Oxford et. al., Lang, 343358.

Wirtz, Thomas (2000), "Allein vor weitem Flur. Marcel Beyer spioniert in fremden Alben". Rezension von Marcel Beyers Spione. Frankfurter Allgemeine Zeitung, 28. Oktober. Também disponível em: http://www.faz.net/aktuell/feuilleton/buecher/rezensionen/belletristik/ rezension-belletristik-allein-vor-weitem-flur-112999.html (consulta: 14.10.2015). 
Rogério Paulo Madeira Licenciou-se, em 1990, em Línguas e Literaturas Modernas (Estudos Ingleses e Alemães), na Universidade de Coimbra. Foi bolseiro do ICALP na Univ.Trier (1990/91), leitor de Português na Univ.Würzburg (1993/94) e docente do ensino básico e secundário (1992-1997). Em 1998, obteve o grau de Mestre em Literatura Alemã e Comparada com uma dissertação sobre $O$ Imaginário de Lisboa em Romances de Thomas Mann e de Hanns-Josef Ortheil (MinervaCoimbra/CIEG, 2002). Em 2009, doutorouse em Letras, na Univ. de Coimbra, com a tese Ficção e História: a Figura de Uriel da Costa na Obra de Karl Gutzkow (MinervaCoimbra/CIEG, 2012). Tem publicado vários outros estudos de menor dimensão sobre recepção e de hermenêutica intercultural no contexto lusoalemão e europeu. É Professor Auxiliar da Faculdade de Letras da Univ. de Coimbra, onde lecciona disciplinas de Literatura e Cultura Alemãs, foi membro do Conselho Directivo (2002-2004), sub-director do curso de Línguas Modernas (2011-2013) e Coordenador do Centro de Investigação em Estudos Germanísticos (CIEG) (2012-2014). Actualmente é membro do Centro de Investigação Transdisciplinar «Cultura, Espaço e Memória» (CITCEM).

\section{NOTAS}

10 presente artigo insere-se no projeto de investigação "Memória, Literatura e Diálogo Internacional", coordenado pelo Professor Doutor John Greenfield, do CITCEM - Centro de Investigação Transdisciplinar «Cultura, Espaço e Memória», Unidade de I \& D financiada pela Fundação para a Ciência e a Tecnologia.

${ }^{2}$ Reporto-me aos primeiros grandes êxitos literários dos autores em apreço: a novela Die Entdeckung der Currywurst (1992), de Uwe Timm, e o romance Flughunde (1995), de Marcel Beyer.

${ }^{3}$ Cf. também Taberner (2007: 1-20).

4 Para uma clarificação dos conceitos de "kommunikatives Gedächtnis" [memória comunicativa] e de "kulturelles Gedachtnis" [memória cultural] e "kollektives Gedächtnis" [memória colectiva], veja-se os estudos 
de A. Assmann (1999) e A. Erll (2005), duas das principais referências da reflexão teórica alemã sobre a memória.

${ }^{5}$ De entre as fontes autobiográficas e/ou historiográficas citadas por Uwe Timm, encontram-se diversos textos de referência como, por exemplo, "Auschwitz - an der Grenze des Geistes" [Auschwitz - no limite do espírito] (1965), de Jean Amery; Ganz normale Männer. Das Reserve-Polizeibataillon 101 und die »Endlösung" in Polen (1996) [original inglês: Ordinary Men: Reserve Police Battalion 101 and the Final Solution in Poland (1992)], de Christopher R. Browning; Die Wehrmacht. Feindbilder - Vernichtungskrieg - Legenden (2002), de Wolfram Wette; Die Untergegangenen und die Geretteten (1990) [original italiano: I sommersi e i salvati (1986); edição portuguesa: Os que Sucumbem e os que se Salvam (2008)], de Primo Levi.

${ }^{6}$ A primeira edição alemã da obra de Nobokov,originalmente publicada em 1967, veio a lume em 1991, sob o título Erinnerung, sprich. Wiedersehen mit einer Autobiographie [Fala, Memória. Reencontro com uma Autobiografia].

7 Todas as citações da obra em análise (veja-se Timm 2003) serão indicadas apenas através das siglas $B B$, seguidas do(s) número(s) da(s) página(s). A tradução das citações - extraídas deste e de outros textos —é da minha responsabilidade, salvo indicação em contrário.

${ }^{8}$ A este respeito, bem como sobre a tendência para a relativização da culpa dos soldados nazis, entre outros, veja-se Kammler (2006: 37ss.; 56ss.) e a carta dirigida a Uwe Timm pelo escritor e amigo norte-americano Robert Cowen, que afasta liminarmente a possibilidade de inocentar Karl-Heinz Timm:

[U]nd du findest nichts, was seine unmittelbare Beteiligung am Holocaust belegt. Hier sagt mir mein eigenes Wissen über den Holocaust: Dieser Bruder war beteiligt, der hat Juden, Russen usw. umgebracht, nicht nur im Kampf, sondern als Massenmörder. Wer, wenn nicht ein Mitglied der SS sollen denn die Täter gewesen sein?" (apud Kammler 2006: 113)

[E tu não encontras nada que possa comprovar a participação dele no Holocausto. Aqui é o meu próprio conhecimento sobre o Holocausto que me diz: esse irmão participou activamente, matou judeus, russos etc., não só em combate, mas também como assassino em massa. Quem, senão os membros da SS é que terão sido então os carrascos?].

9 Todas as citações da obra em análise (veja-se Beyer 2002) serão indicadas apenas através da sigla $S$, seguida do(s) número(s) da(s) página(s). A tradução utilizada é a que consta da bibliografia (cf. Beyer 2003), salvaguardando pequenas modificações pontuais.

${ }^{10}$ A este respeito, veja-se também Filomena Vieira Guarda (2010: 275-286). 